\title{
Efeito de extratos aquosos de espécies de Asteraceae sobre Meloidogyne incognita
}

\author{
Isabel Cristina Madeira Ferreira ${ }^{1}$, Gilson Soares da Silva ${ }^{1}$, Fagner Sousa Nascimento ${ }^{1}$
}

${ }^{1}$ Universidade Estadual do Maranhão, Programa de Pós-Graduação em Agroecologia, Caixa Postal 3004, São Luís (MA) Brasil. Autor para correspondência: Isabel Cristina Madeira Ferreira (isabel_agro23@hotmail.com)

Data de chegada: 20/10/2011. Aceito para publicação em: 30/03/2013.

\section{RESUMO}

Ferreira, I.C.M.; Silva, G.S.; Nascimento, F.S. Efeito de extratos aquosos de espécies de Asteraceae sobre Meloidogyne incognita. Summa Phytopathologica, v.39, n.1, p.40-44, 2013.

Estudou-se, in vitro e in vivo a atividade nematicida dos extratos aquosos de vedélia(Sphagneticola trilobata), erva-de-touro (Tridax procumbens), cravo-de-defunto (Tagetes patula), girassol mexicano (Tithonia diversifolia), botão de ouro (Unxia suffruticosa) e zínia (Zinnia peruviana), sobre Meloidogyne incognita. Os extratos foram preparados na proporção de $1,0 \mathrm{~g}$ do material seco e triturado para $10 \mathrm{~mL}$ de água destilada e armazenados por $24 \mathrm{~h}$, sendo seguidamente utilizados nos experimentos. Nos testes in vitro, foram depositados $4,0 \mathrm{~mL}$ do extrato bruto e $2,0 \mathrm{~mL}$ de uma suspensão aquosa contendo 200 ovos do nematóide em placas de Petri de $5 \mathrm{~cm}$ de diâmetro e, quinze dias após, procedeu-se a contagem do número de juvenis eclodidos e dos ovos remanescentes para o cálculo das porcentagens de eclosão. Nos testes in vivo, os extratos foram aplicados, separadamente, via pulverização foliar, tratamento de raiz e vertido no solo, semanalmente durante 60 dias. Como testemunha utilizou-se apenas água nos dois experimentos. No ensaio in vitro observou-se que todos os extratos foram eficientes na redução da eclosão de juvenis de $M$. incognita quando comparados à testemunha, as porcentagens de redução foram $89,96 \%, 91,13 \%, 92,48 \%, 92,72 \%, 93,2 \%$ e $97,48 \%$ para erva-de-touro, cravo-de-defunto, girassol mexicano, vedélia, botão de ouro e zínia, respectivamente, e no ensaio in vivo, que os tratamentos não exerceram nenhum efeito sobre o peso do sistema radicular dos tomateiros, no entanto, observou-se que os resultados diferiram entre as espécies utilizadas e a forma de aplicação do extrato na avaliação do peso fresco da parte aérea das plantas. Quanto ao fator de reprodução, observou-se que nenhum dos extratos apresentou diferença estatística em relação à testemunha, no entanto, quando se compara as diferentes formas de aplicação dos mesmos, observa-se que houve diferença estatística quando os extratos de erva de touro e girassol mexicano foram aplicados via pulverização foliar e no tratamento de raiz, contudo, não houve diferença quando estes extratos foram aplicados em forma de rega no solo.

Palavras-chave adicionais: plantas antagonistas; nematóides das galhas, extratos botânicos.

\section{ABSTRACT}

Ferreira, I.C.M.; Silva, G.S.; Nascimento, F.S. Effect of aqueous extracts of Asteraceae species on Meloidogyne incognita. Summa Phytopathologica, v.39, n.1, p.40-44, 2013

The nematicide activity of aqueous extracts of Wedelia (Sphagneticola trilobata), tridax daisy (Tridax procumbens), marigold (Tagetes patula), Mexican sunflower (Tithonia diversifolia), "botão de ouro" (Unxia suffruticosa) and Peruvian zinnia (Zinnia peruviana) was studied in vitro and in vivo on Meloidogyne incognita. The extracts were prepared at a ratio of $1.0 \mathrm{~g}$ of dry and crushed material to $10 \mathrm{ml}$ of distilled water, stored for 24 hours, and then used in the experiments. In in vitro tests, $4.0 \mathrm{~mL}$ of crude extract and $2.0 \mathrm{ml}$ of an aqueous suspension containing 200 nematode eggs were deposited on Petri plates of $5 \mathrm{~cm}$ diameter and, fifteen days later, the number of hatched juveniles and the remaining eggs were counted to calculate the percentages of hatching. In in vivo tests, the extracts were separately applied by leaf spraying, root treatment and pouring onto the soil, weekly for 60 days. As control, only water was used in both experiments. The in vitro test showed that all extracts were effective in reducing the hatching of juveniles of $M$. incognita when compared to the control; the reduction percentages were $89.96 \%, 91.13 \%, 92.48 \%, 92.72 \%, 93.2 \%$ and $97.48 \%$ for tridax daisy, marigold, Mexican sunflower, Wedelia, "botão de ouro" and Peruvian zinnia, respectively, while in the in vivo assay, treatments did not have any effect on the root system weight of tomato plants; however, results differed between the used species and the way of application of the extract in the evaluation of the fresh weight of shoots. As to the reproduction rate, none of the extracts showed a statistical difference, compared to control; however, comparing the different ways of application, there was statistical difference when the extracts of tridax daisy and Mexican sunflower were applied through leaf spraying and root treatment, but there was no difference when these extracts were applied as irrigation on the soil.

Additional keywords: antagonistic plant; root-knot nematodes, plant extracts.

Com a crescente preocupação da sociedade com os aspectos ambientais, somado ao crescimento da agricultura orgânica em todo o mundo, muitas pesquisas têm sido realizadas à procura de compostos naturais, biologicamente ativos Lopes (12). Dentre as táticas de manejo, a utilização de extratos aquosos tem apresentado resultados promissores Ferris \& Zheng (4).

Plantas antagônicas afetam a população de nematoides negativamente como plantas armadilha, más hospedeiras, e aquelas 
que contem compostos nematicidas/nematostáticos em seus tecidos Zambolim et al. (19). Várias espécies apresentam substâncias nematicidas como alcalóides, ácidos graxos, isotiocianatos, glicosídeos acianogênicos, terpenóides, compostos fenólicos e outros DallemoleGiaretta et al. (19). Estes compostos podem ser utilizados isolando os componentes ativos, identificados e sintetizados quimicamente pela indústria, ou então, podem ser aplicados diretamente pelos agricultores Pascual- VillaLobos (16).

A descoberta da utilidade dos metabólitos secundários para o desenvolvimento fisiológico das plantas e o seu papel como mediadoras das interações entre as plantas e outros organismos tem contribuído para o avanço nas pesquisas neste âmbito Gardiano et al.(8), como nota-se nos trabalhos desenvolvidos por Lopes et al. (13), que observaram que a pulverização de extratos de mucuna preta e manjericão reduziu o número de galhas de $M$. incognita em raízes de tomateiro, quando comparado à testemunha(água) e que a adição de extratos de sementes de mucuna preta ao solo reduziu a reprodução de $M$. javanica.

A família Asteraceae compreende cerca de 25.000 espécies distribuídas em aproximadamente 1.100 gêneros, sendo representada no Brasil por cerca de 180 delas. As espécies pertencentes a esta família apresentam grande potencial químico e biológico por serem ricos em estruturas químicas e com atividades biológicas e farmacêuticas Gott et al. (10), aparecendo com um número relativamente grande de citações bibliográficas, envolvendo farmacognosia, fitoquímica e plantas medicinais Carvalho et al. (2), o que desperta o interesse por pesquisas com estas plantas no manejo de doenças de plantas, como pode ser observado em testes realizados por Franzener et al. (5), em estudos que avaliaram o efeito protetor do extrato aquoso de Tagetes patula em tomateiro a $M$. incognita, observaram o potencial que o extrato desta planta possui de proteger o tomateiro e que, possivelmente, além de efeito nematicida e/ou nematostático, envolve o aumento da resistência das plantas ao nematóide.

$\mathrm{O}$ uso de extratos vegetais com propriedades nematicidas no controle de fitonematóides representa mais uma alternativa para os pequenos produtores com valor prático e econômico, e sem riscos de contaminação do ambiente Pascual- VillaLobos (16); Gardiano et al. (9), porém, apesar de muitos trabalhos terem sido publicados indicando a atividade de diversos extratos contendo metabólitos secundários, pouco se sabe sobre as moléculas atuantes, muito menos sobre o mecanismo de ação das mesmas, o que reforça também a necessidade de estudos na área de prospecção de biomoléculas oriundas de fontes vegetais Rocha et al. (17).

O objetivo deste trabalho foi avaliar o efeito do extrato aquoso de seis espécies de plantas da família Asteraceae, in vitro, sobre a eclosão de juvenis de Meloidogyne incognita, e in vivo, avaliando o efeito destes extratos e de três formas de aplicação do mesmo no controle de M. incognita em tomateiro.

\section{MATERIAL E MÉTODOS}

Os experimentos foram desenvolvidos em casa de vegetação e no Laboratório de Fitopatologia, do Núcleo de Biotecnologia Agronômica da Universidade Estadual do Maranhão - UEMA. O teste in vitro obedeceu a um delineamento inteiramente casualizado, com sete tratamentos e cinco repetições e o teste in vivo obedeceu a um delineamento experimental inteiramente casualizado em esquema fatorial $(6 \times 3 \times 1)$, sendo os extratos obtidos de seis diferentes espécies de Asteraceae, três formas de aplicação dos mesmos e um tratamento controle, representado pelo tomateiro tratado apenas com água, totalizando 19 tratamentos com cinco repetições.

Obtenção e multiplicação do inóculo de Meloidogyne incognita

A população de $M$. incognita utilizada nos experimentos foi obtida de raízes de abóbora (Curcubita pepo L.) coletadas no município de Paço do Lumiar- MA, e multiplicada em tomateiro cv. Santa Cruz Kada Gigante, em casa de vegetação durante sessenta dias. Após este período, os ovos foram extraídos pelo método de Hussey \& Barker (11) modificado por Bonetti \& Ferraz (1). A concentração do inóculo foi ajustada para 100 ovos/mL para os testes in vivo e de 500 ovos/ $\mathrm{mL}$ para os testes in vitro.

\section{Preparo dos extratos}

O material vegetal foi coletado nos municípios de São Luís e Paço do Lumiar, Maranhão. As espécies coletadas foram erva-de-touro (Tridax procumbens), girassol mexicano (Tithonia diversifolia), cravo de defunto (Tagetes patula), zínea (Zinnia peruveana), botão de ouro (Unxia suffruticosa) e vedélia (Sphagneticola trilobata). As plantas foram secas à sombra e trituras após 15 dias, com auxílio de um liquidificador. Para obtenção dos extratos seguiu-se a metodologia descrita por Ferris \& Zheng (4), no qual misturou-se 1,0g de parte aérea seca triturada de cada espécie, separadamente, com $10 \mathrm{~mL}$ de água destilada previamente fervida. Os extratos foram acondicionados em erlenmeyers cobertos com papel alumínio e mantidos em repouso no escuro por 24 horas. Nos testes in vivo, os extratos eram preparados no dia anterior à aplicação dos mesmos.

\section{Instalação dos experimentos \\ Testes in vitro}

Nos testes in vitro, foram utilizadas placas de acrílico de $5 \mathrm{~cm}$ de diâmetro como câmaras de eclosão, e as mesmas acondicionadas em uma bandeja plástica forrada com papel toalha umedecido. Foram depositados 4,0 $\mathrm{mL}$ dos respectivos extratos e 2,0 $\mathrm{mL}$ da suspensão aquosa, contendo 200 ovos de $M$. incognita. A testemunha constou apenas da suspensão de ovos e água destilada. Os ovos foram incubados a $26^{\circ} \mathrm{C}$ por um período de 15 dias, sendo o experimento umedecido diariamente com o auxílio de uma pisseta.

\section{Testes in vivo}

No experimento in vivo, utilizou-se como substrato solo autoclavado $\left(120^{\circ} \mathrm{C} / 2 \mathrm{~h}\right)$, contido em vasos plásticos de $2 \mathrm{~L}$ de capacidade. As mudas de tomateiro foram obtidas em bandejas de polietileno com 128 células, contendo substrato comercial PlantMax ${ }^{\circledR}$.

\section{Aplicação dos extratos}

\section{Via pulverização foliar}

Com o auxílio de um pulverizador manual, os extratos foram aplicados nas superfícies abaxial e adaxial das folhas de tomateiro, até o ponto de escorrimento. Os vasos foram protegidos com sacos plásticos para evitar o contato dos extratos com o solo. As aplicações foram feitas semanalmente, durante um período de 60 dias.

\section{Rega do solo}

Adicionou-se ao solo de cada vaso, na forma de rega, $20 \mathrm{~mL}$ dos extratos, por um período de 60 dias, a intervalos semanais.

\section{Tratamento de raiz}

O sistema radicular das mudas de tomateiro foram imersos nos diferentes extratos de Asteraceas, durante 15 minutos. Após este 
período, os mesmos foram imediatamente transplantados para vasos previamente infestados com $M$. incognita.

\section{Avaliação dos experimentos}

No experimento in vivo os juvenis eclodidos e os ovos remanescentes foram quantificados com o auxílio de um microscópio estereoscópio, após 15 dias de incubação e, em seguida, calculou-se a porcentagem de juvenis eclodidos pela fórmula: Porcentagem de eclosão $=$ [número de juvenis eclodidos/(número de juvenis eclodidos + número de ovos remanescentes)] x 100 e o experimento in vivo foi avaliado, 60 dias após a instalação, tendo como parâmetros o peso de parte aérea, e do sistema radicular e os ovos extraídos para os cálculos do fator de reprodução. Os dados foram submetidos ao Programa ASSISTAT 7.5 e as médias comparadas pelo teste de Tukey ao nível de $5 \%$ de probabilidade.

\section{RESULTADOS E DISCUSSÃO}

No ensaio in vitro, foi possível observar que todos os extratos inibiram a eclosão de juvenis de $M$. incognita, quando comparados à testemunha (Tabela 1).

Estes resultados confirmam aqueles obtidos por Franzener et al. (5), que também observaram uma redução na eclosão de $M$. incognita quando imersos em extratos de Tagetes patula. Resultados semelhantes foram observados Scramin et al.(18), avaliando in vitro o efeito de extratos de 14 espécies de plantas sobre $M$. incognita raça 1 notaram que o extrato hexânico de T. minuta foi o mais eficiente, apresentando $91,6 \%$ de atividade nematicida.

Outros autores obtiveram resultados satisfatórios em testes realizados com extratos botânicos sobre nematoides, como se observa em experimentos conduzidos por Neves et al. (14), que avaliaram a atividade do extrato aquoso de sementes de mamão sobre a eclosão e inativação dos juvenis de $M$. incognita e $M$. javanica e observaram que o extrato reduziu a eclosão e promoveu a morte de juvenis destes patógenos em testes in vitro. Testes semelhantes foram realizados por Dallemole- Giaretta et al. (3), na avaliação do extrato aquoso de sementes de abóbora, obtendo a redução na eclosão e inativação de juvenis de $M$. incognita e $M$. javanica, nos testes in vitro.

No ensaio in vivo avaliou-se o peso de parte aérea e do sistema

Tabela 1. Efeito do extrato de espécies da família Asteraceae sobre a eclosão de juvenis de segundo estádio de M. incognita após 15 dias de imersão

\begin{tabular}{lcc}
\hline Extratos & $\begin{array}{c}\text { J2 Eclodidos } \\
\mathbf{( \% )}\end{array}$ & $\begin{array}{c}\text { Redução da Eclosão } \\
\text { (\%) }\end{array}$ \\
\hline Vedélia & $3,03 \mathrm{~b}$ & 92,72 \\
Erva-de-touro & $4,22 \mathrm{~b}$ & 89,96 \\
Girassol mexicano & $3,13 \mathrm{~b}$ & 92,48 \\
Cravo-de-defunto & $3,69 \mathrm{~b}$ & 91,13 \\
Botão de ouro & $2,83 \mathrm{~b}$ & 93,2 \\
Zínea & $1,09 \mathrm{~b}$ & 97,38 \\
Testemunha & $41,60 \mathrm{a}$ & $* * *$ \\
\hline CV (\%) & $\mathbf{2 4 , 6 3}$ & $* * *$ \\
\hline
\end{tabular}

As médias seguidas de uma mesma letra, na coluna, não diferem estatísticamente, à nível de $5 \%$ de probabilidade, pelo teste de Tukey. radicular dos tomateiros e o fator de reprodução do nematoide. Ao avaliar o peso fresco de parte aérea dos tomateiros (Tabela 2), observouse que apenas o extrato de Botão de Ouro aplicado via foliar apresentou diferença estatística significativa em relação à testemunha, no entanto, quando se aplicou os extratos em forma de rega no solo, verifica-se que todos os tratamentos diferiram em relação à testemunha, incrementando o peso de parte aérea das plantas avaliadas. Quando se realizou a imersão do sistema radicular nos diferentes extratos não se observou diferença estatística entre os tratamentos. Não houve diferença estatística significativa quando se aplicou os extratos via pulverização foliar e tratamento de raiz, no entanto, as duas formas de aplicação diferiram estatisticamente da aplicação em forma de rega no solo, que proporcionou um incremento no peso de parte aérea dos tomateiros.

Tabela 2. Peso fresco da parte aérea(g) de plantas de tomateiro, tratadas com extratos aquosos de 6 espécies vegetais após a infestação do solo com Meloidogyne incognita.

\begin{tabular}{lccc}
\hline \multirow{2}{*}{ Extratos } & \multicolumn{3}{c}{ Forma de aplicação do extrato } \\
\cline { 2 - 4 } & $\begin{array}{c}\text { Pulverização } \\
\text { foliar }\end{array}$ & $\begin{array}{c}\text { Tratamento } \\
\text { de Raiz }\end{array}$ & $\begin{array}{c}\text { Rega } \\
\text { do solo }\end{array}$ \\
\hline Vedélia & $4,43 \mathrm{Bb}$ & $6.14 \mathrm{Ba}$ & $9.85 \mathrm{Aa}$ \\
Erva-de-touro & $5.78 \mathrm{Bab}$ & $6.60 \mathrm{Ba}$ & $10.24 \mathrm{Aa}$ \\
Girassol mexicano & $5.64 \mathrm{Bab}$ & $5.38 \mathrm{Ba}$ & $10.23 \mathrm{Aa}$ \\
Cravo-de-defunto & $5.79 \mathrm{Bab}$ & $7,28 \mathrm{Ba}$ & $9.85 \mathrm{Aa}$ \\
Botão de ouro & $8.53 \mathrm{Ba}$ & $7.28 \mathrm{Ba}$ & $12.61 \mathrm{Aa}$ \\
Zínea & $7.02 \mathrm{Bab}$ & $7.09 \mathrm{Ba}$ & $13.27 \mathrm{Aa}$ \\
Testemunha & $5.02 \mathrm{Ab}$ & $5.02 \mathrm{Aa}$ & $5.02 \mathrm{Ab}$ \\
\hline CV (\%) & 24,48 & 24,48 & 24,48 \\
\hline
\end{tabular}

Médias seguidas pela mesma letra minúscula nas colunas e maiúscula nas linhas não diferem a $5 \%$ de probabilidade pelo teste de Tukey.

Resultados semelhantes foram encontrados por Gardiano et al. (9), em experimento avaliando o efeito da adição ao solo dos extratos aquosos de 20 espécies de plantas sobre a população de $M$. javanica em plantas de tomateiro. Os autores observaram que as aplicações de todos os extratos incrementaram o peso de parte aérea do tomateiro, em relação à testemunha. Já Lopes et al.(13), verificaram que a aplicação de extratos aquosos de mucuna preta e manjericão sobre a parte aérea de tomateiro não afetaram nem a altura nem o peso da parte aérea dos tomateiros.

Quanto ao peso fresco do sistema radicular dos tomateiros, os resultados mostram que nenhum dos extratos e nem a forma de aplicação dos mesmos proporcionou o incremento deste fator, como pode ser observado na Tabela 3.

Gardiano (6), em testes semelhantes, verificou que a pulverização foliar de extratos aquosos de artemísia, bardana, cavalinha, carqueja, cidreira, hortelã, calapogônio e mamona não proporcionaram aumento do peso do sistema radicular dos tomateiros inoculados com $M$. javanica, em contraste à cinamono, manjericão e melão de São Caetano que não diferiram estatísticamente da testemunha inoculada, obtendo maiores pesos no sistema radicular quando comparados aos outros tratamentos.

Ao analisar o fator de reprodução de $M$. incognita em tomateiros tratados com extratos aquosos de diferentes espécies de Asteraceae, observa-se que nenhum dos extratos apresentou diferença estatística 
Tabela 3. Peso fresco do sistema radicular(g) de plantas de tomateiro, tratadas com extratos aquosos de 6 espécies vegetais após a infestação do solo com Meloidogyne incognita.

\begin{tabular}{lccc}
\hline \multirow{2}{*}{ Extratos } & \multicolumn{2}{c}{ Forma de aplicação } & \\
\cline { 2 - 4 } & $\begin{array}{c}\text { Pulverização } \\
\text { foliar }\end{array}$ & $\begin{array}{c}\text { Tratamento } \\
\text { de } \text { Raiz }\end{array}$ & $\begin{array}{c}\text { Rega } \\
\text { do solo }\end{array}$ \\
\hline Vedélia & 3,65 & 5,20 & 4,39 \\
Erva-de-touro & 4,50 & 5,08 & 5,74 \\
Girassol mexicano & 4,28 & 4,54 & 4,60 \\
Cravo-de-defunto & 5,10 & 5,22 & 5,02 \\
Botão de ouro & 6,50 & 5,24 & 5,62 \\
Zínea & 5,00 & 5,60 & 6,58 \\
Testemunha & 3,30 & 3,30 & 3,30 \\
\hline CV (\%) & 20,10 & 20,10 & 20,10 \\
\hline
\end{tabular}

Médias seguidas pela mesma letra minúscula nas colunas e maiúscula nas linhas não diferem a $5 \%$ de probabilidade pelo teste de Tukey.

em relação à testemunha. No entanto, quando se compara as diferentes formas de aplicação dos extratos, observa-se que houve diferença estatística quando os extratos de erva de touro e girassol mexicano foram aplicados via pulverização foliar e no tratamento de raiz, contudo, não houve diferença quando estes extratos foram aplicados em forma de rega no solo. Nos demais tratamentos não houve diferença estatística significativa.

Os resultados negativos obtidos podem estar associados ao método de extração, o solvente utilizado, à espécie botânica, as técnicas de coleta e secagem e vários outros fatores podem interferir na liberação do princípio ativo da planta. A atividade nematicida de Tagetes spp. tem sido demonstrada por vários autores, a exemplo de Scramim et al.(18), que avaliando in vivo a atividade nematicida ou nematostática de 62 extratos obtidos de diferentes espécies e partes vegetais obtidos na extração com solventes orgânicos, observaram que o extrato hexânico de folhas de T. minuta e o extrato clorofórmico de caule de T. patula, mostraram atividade potencial. Os mesmos autores também verificaram que o extrato clorofórmico de folhas de Ageratum conyzoides mostrou atividade nematicida de $85,1 \%$, em contraste aos extratos hexânico e etanólico que não apresentaram atividade expressiva, correspondendo

Tabela 4. Fator de reprodução de Meloidogyne incognita em tomateiros tratados com extratos aquosos de 6 espécies de Asteraceae durante 60 dias.

\begin{tabular}{lccc}
\hline \multirow{2}{*}{ Asteraceae } & \multicolumn{2}{c}{ Forma de aplicação } & \\
\cline { 2 - 5 } & $\begin{array}{c}\text { Pulverização } \\
\text { foliar }\end{array}$ & $\begin{array}{c}\text { Tratamento } \\
\text { de Raiz }\end{array}$ & $\begin{array}{c}\text { Rega } \\
\text { do solo }\end{array}$ \\
\hline Vedélia & $6.58 \mathrm{Aab}$ & $5.33 \mathrm{Aa}$ & $7.08 \mathrm{Aa}$ \\
Erva-de-touro & $3.78 \mathrm{Bb}$ & $8.29 \mathrm{Aa}$ & $5.72 \mathrm{ABa}$ \\
Girassol mexicano & $5.17 \mathrm{Bab}$ & $7.92 \mathrm{Aa}$ & $7.22 \mathrm{ABa}$ \\
Cravo-de-defunto & $6.05 \mathrm{Aab}$ & $7.55 \mathrm{Aa}$ & $5.44 \mathrm{Aa}$ \\
Botão de ouro & $7.59 \mathrm{Aa}$ & $7.44 \mathrm{Aa}$ & $5.68 \mathrm{Aa}$ \\
Zínea & $6.65 \mathrm{Aab}$ & $6.89 \mathrm{Aa}$ & $5.08 \mathrm{Aa}$ \\
Testemunha & $5.71 \mathrm{Aab}$ & $5.71 \mathrm{Aa}$ & $5.71 \mathrm{Aa}$ \\
\hline CV (\%) & 27,11 & 27,11 & 27,11 \\
\hline
\end{tabular}

Médias seguidas pela mesma letra minúscula nas colunas e maiúscula nas linhas não diferem a $5 \%$ de probabilidade pelo teste de Tukey. a $10,3 \%$ e $19,6 \%$ de atividade nematicida. Experimentos realizados por Neves et al. (15) avaliando o efeito de extratos de alho, mostarda e pimenta malagueta, óleo de mostarda além de produtos à base de capsaicin, capsainoides e alilisotiocianatos sobre M. javanica, observaram que os produtos mostraram resultados variáveis, de acordo com o produto e o solvente utilizado no preparo dos extratos. Extrato de Crotalaria mucronata reduziu o número de galhas em raízes de tomateiro inoculado com $M$. javanica mas várias outras espécies de crotalária não tiveram efeito sobre o fitonematoide Gardiano et al. $(7 ; 8)$.

Os resultados mostram que, nos testes in vivo, todos os extratos foram eficientes em reduzir a eclosão de Meloidogyne incognita, e nos testes in vivo, conclui-se que os extratos aquosos obtidos de espécies de Asteraceae não apresentaram resultados satisfatórios na inibição da reprodução do nematoide em tomateiro. Não houve nenhum efeito exercido sobre o peso do sistema radicular das plantas, no entanto, no incremento do peso de parte aérea dos tomateiros, os resultados foram variáveis.

\section{REFERÊNCIAS BIBLIOGRÁFICAS}

1. Bonetti, J.I.S.; Ferraz, S. Modificação do método de Hussey e Barker para extração de ovos de Meloigogyne exigua de raízes de cafeeiro. Fitopatologia Brasileira, Lavras, v.6, p.553, 1981.

2. Carvalho, G.J.A.; Carvalho, M.G.; Ferreira, D.T.; Faria, T.J.; BrazFilho, R. Diterpenos, triterpenos e esteroides das flores de Wedelia paludosa. Química Nova, São Paulo, v.24, n.1, p.24-26, 2001 .

3. Dallemole-Giaretta, R.; Freitas, L.G.; Neves, W.S.; Coutinho, M.M.; Ferraz, S. Efeito de extrato aquoso de sementes de abóbora sobre a eclosão e inativação de juvenis de Meloidogyne javanica e de M. incognita. Revista Trópica- Ciências Agrárias e Biológicas, Chapadinha, v.3, n.1, p.3-7, 2009.

4. Ferris, H.; Zheng, L. Plant sourcers of Chinese herbal remedies: effects on Pratylenchus vulnus and Meloidogyne javanica. Journal of Nematology, Marceline, v.31, p.241-263, 1999.

5. Franzener, G.; Martinez-Franzener, A.S.; Stangarlin, J.R.; Furlanetto, C.; Schwan- Estrada, K.R.F. Proteção de tomateiro a $\mathrm{Me}$ loidogyne incognita pelo extrato aquoso de Tagetes patula. Nematologia Brasileira, Brasília, v.31, n.1, p.27-36, 2007.

6. Gardiano, C.G. Atividade nematicida de extratos aquosos e tinturas vegetais sobre Meloidogyne javanica (Treub, 1885) Chitwood, 1949. 2006. 78f. Dissertação(Mestrado em Fitopatologia). Universidade Federal de Viçosa, Viçosa.

7. Gardiano, C. G. , Dallemole-Giareta, R., Lopes, E. A. Zooca, R. J. F. , Ferraz, S.; Freitas, L. G. Atividade nematicida de extratos de sementes de espécies de Crotalaria sobre Meloidogyne javanica. Revista Trópica-Ciências Agrárias e Biológicas, Chapadinha, v.4, p.3-7, 2010 .

8. Gardiano, C.G., Ferraz, S., Lopes, E. A., Ferreira, P. A., Carvalho, S. L. Pulverização de tinturas vegetais em tomateiros para o controle de $M$. javanica. Revista Trópica - Ciências Agrárias e Biológicas, Chapadinha, v.2, n.3, p.22-27, 2008.

9. Gardiano, C.G., Ferraz, S., Lopes, E. A., Ferreira, P. A.; Amora, D.X.; Freitas, L.G. Avaliação de extratos aquosos de várias espécies vegetais, aplicados ao solo, sobre Meloidogyne javanica (Treub, 1885) Chitwood, 1949. Semina: Ciências Agrárias, Londrina, v.30, v.3, p.551-556, 2009.

10. Gott, R.M.; Tavares, W.S.; Pereira, A.I.A.; Teodoro, R.B. Petacci, F.; Freitas, S.S. Potencial químico de plantas daninhas Asteraceae de campos rupestres de Diamantina, Minas Gerais. In: XXVII Congresso Brasileiro da Ciência das Plantas Daninhas, 2010, Anais. Ribeirão Preto, 2010. p. 3129-3133.

11. Hussey, R.S.; Barker, R.K. A comparison of methods of collecting inocula of Meloidogyne spp. including a new technique. Plant 
Disease Reporter, St. Paul, v.57, n.12, p. 1025-1028, 1973.

12. Lopes, E.A. Potencial de extratos aquosos e da incorporação ao solo de mucuna preta(Mucuna pruriens var. utilis) para o controle do nematóide das galhas. 2004. 42f. Dissertação (Mestrado em Fitopatologia)- Universidade Federal de Viçosa, Viçosa.

13. Lopes, E.A.; Ferraz, S.; Freitas, L.G.; Ferreira, P.A.; Amora, D.X. Efeito dos extratos aquosos de mucuna preta e de manjericão sobre Meloidogyne incognita e Meloidogyne javanica. Nematologia Brasileira, Brasília, v.29, n.1, p.67-74, 2005.

14. Neves, W.S.; Freitas, L.G.; Lopes, E.A.; Coutinho, M.M. Dallemole-Giaretta, R.; Ferraz, S. Efeito, in vitro, do extrato de sementes de mamão sobre a eclosão de juvenis de Meloidogyne spp. Revista Trópica - Ciências Agrárias e Biológicas, Chapadinha, v.2, n.3, p.9, 2008.

15. Neves, W. S., Freitas, L. G. , Coutinho, M. M., Dallemole-Giaretta, R., Fabry, C. F. S. , Dhingra, O. D.; Ferraz, S. Ação nematicida de extratos de alho, mostarda, pimenta malagueta, de óleo de mostarda e de dois produtos à base de capsainoides e alilisotioci- anatos sobre juvenis de M. javanica (Treub) Chitwood, 1949, em casa de vegetação. Summa Phytopathologica, Botucatu, v.35, n.4, p.255-261, 2009

16. Pascual-Vilalobos, M.J. Plaguicidas naturales de origen vegetal: estado actual de La investigación. 1996. 35 f. Monografia- Instituto Nacional de Investigación Agrária y Alimentaria, Madri.

17. Rocha, T.L.; Murad, A.M.; Evaristo, R.G.S.; Almeida, W. S.; Magalhães, J.C.C.; Mattar, M.C.S.; Grossi-de-Sá, M.F. Efeito nematicida de extratos aquosos de sementes de plantas sobre juvenis de segundo estádio de Meloidogyne incognita. Comunicado técnico 144, Brasília, 2006.

18. Scramim, S.; Silva, H.P.; Fernandes, L.M.S. Yhan, C.A. Avaliação biológica de extratos de 14 espécies vegetais sobre Meloidogyne incognita raça 1. Nematologia Brasileira, Brasília, v.11, 1987.

19. Zambolim, L., Costa, H.; Jesus Júnior, W.C. Manejo integrado das doenças de hortaliças. In.: Zambolim, L.; Lopes, C.A.; Picanço, M.C.; Costa, H. Manejo integrado de doenças e pragas de hortaliças. Viçosa: Editora UFV, 2007. Cap.07, p.225-318. 